\title{
Naturalistic follow-up of co-morbid substance use in schizophrenia: the West London first-episode study
}

\author{
I. Harrison ${ }^{1}$, E. M. Joyce ${ }^{2}$, S. H. Mutsatsa ${ }^{1}$, S. B. Hutton ${ }^{3}$, V. Huddy ${ }^{1}$, M. Kapasi ${ }^{1}$ and T. R. E. Barnes ${ }^{1 *}$ \\ ${ }^{1}$ Department of Psychological Medicine, Imperial College Faculty of Medicine, London, UK \\ ${ }^{2}$ Institute of Neurology, University College London, London, UK \\ ${ }^{3}$ Department of Psychology, University of Sussex, Brighton, UK
}

Background. The impact of co-morbid substance use in first-episode schizophrenia has not been fully explored.

Method. This naturalistic follow-up of a cohort of 152 people with first-episode schizophrenia examined substance use and clinical outcome in terms of symptoms and social and neuropsychological function.

Results. Data were collected on 85 (56\%) of the patient cohort after a median period of 14 months. Over the follow-up period, the proportion of smokers rose from $60 \%$ at baseline to $64 \%$. While $30 \%$ reported lifetime problem drinking of alcohol at baseline, only $15 \%$ had problem drinking at follow-up. Furthermore, while at baseline $63 \%$ reported lifetime cannabis use and $32 \%$ were currently using the drug, by the follow-up assessment the latter figure had fallen to $18.5 \%$. At follow-up, persistent substance users had significantly more severe positive and depressive symptoms and greater overall severity of illness. A report of no lifetime substance use at baseline was associated with greater improvement in spatial working memory (SWM) at follow-up.

Conclusions. Past substance use may impede recovery of SWM performance in people with schizophrenia in the year or so following first presentation to psychiatric services. The prevalence of substance use other than tobacco tends to diminish over this period, in the absence of specific interventions. Persistent substance use in first-episode schizophrenia is associated with more severe positive and depressive symptoms but not negative symptoms, and should be a target for specific treatment intervention.

Received 21 April 2006; Revised 5 April 2007; Accepted 12 April 2007; First published online 29 May 2007

Key words : First-episode, schizophrenia, substance use.

\section{Introduction}

Substance use in people with established schizophrenia is most likely to involve alcohol and cannabis (Condren et al. 2001; Duke et al. 2001), and this profile is also seen in first-episode patients (Green et al. 2004; Barnes et al. 2006; Wade et al. 2006). Even relatively low levels of such co-morbid substance use are associated with a poorer outcome, including greater risk of relapse and a worse response to first-generation antipsychotic medication (Drake \& Brunette, 1998; Hunt et al. 2002; Kavanagh et al. 2004). This seems to hold true for first-episode patients, even in the short term (Caspari, 1999; Sorbara et al. 2003). The potential impact on cognitive function is less clear. As McCleery et al. (2006) point out, while substance use in the general population can have a negative impact on

\footnotetext{
* Address for correspondence: Professor T. R. E. Barnes, Division of Neuroscience and Mental Health, Imperial College Faculty of Medicine, Charing Cross Campus, St Dunstan's Road, London W6 8RP, UK.

(Email: t.r.barnes@imperial.ac.uk)
}

cognitive function, studies of early schizophrenia have generally failed to find any relationship between substance use and neuropsychological functioning (Sevy et al. 2001; Pencer \& Addington, 2003). More generally, it has been claimed that people with schizophrenia and substance use would have better social and cognitive functioning than those who are abstinent, greater resources of this kind being necessary to obtain substances and maintain substance use (Salyers \& Mueser, 2001; Sevy et al. 2001). Clinical studies addressing this association have yielded contradictory findings (Potvin et al. 2005; Barnes et al. 2006; McCleery et al. 2006).

The current study assessed substance use and tobacco use in first-episode schizophrenia at initial presentation to psychiatric services, and at follow-up. The aims of the study were:

(1) to ascertain the proportion of patients stopping, starting or continuing substance use and daily tobacco use subsequent to their initial presentation to psychiatric services with schizophrenia; 
(2) to examine whether those with and without a history of substance use at baseline differed significantly in any aspects of clinical outcome, specifically symptoms and cognitive function, in the first year or so of treatment;

(3) to assess the impact of continued substance use on clinical response to treatment, neuropsychological performance and social function.

\section{Method}

\section{Subjects}

Subjects for this epidemiologically-based study were recruited as part of a prospective, longitudinal study of first-episode schizophrenia in West London. We have previously provided details of the design and entry criteria (Hutton et al. 1998). The patients eligible for this study were aged between 16 and 50 years, and most were seen at the time of their first admission to hospital. For each patient, a diagnosis of DSM-IV schizophrenia or schizophreniform disorder was confirmed at diagnostic review by two senior clinicians (E.M.J., T.R.E.B.).

\section{Assessments}

Reports of current alcohol and non-alcohol substance use were recorded using the Substance Use Rating Scale, patient version (SURSp ; Duke et al. 1994, 2001), at baseline and follow-up. This scale initially elicits information about the use of legal drugs such as caffeine and nicotine, and identifies problem and dependent alcohol use. It then moves on to detailed questioning about the nature of current (within the past month) and previous substance use.

Mental state was assessed at both time points as follows. The Scales for the Assessment of Positive and Negative Symptoms (SAPS and SANS; Andreasen, 1990) were used to obtain positive, disorganization and negative syndrome scores (Liddle \& Barnes, 1990) for each patient. The Comprehensive Psychopathological Rating Scale (CPRS; Asberg et al. 1978) was also administered, from which a score for the 10item Montgomery-Asberg Depression Rating Scale (MADRS; Montgomery \& Asberg, 1979) was extracted. Severity of illness was assessed using the Clinician Global Impression scale (CGI).

Social function was assessed using the Social Function Scale (SFS; Birchwood et al. 1990) at both time points. Individuals are asked about their abilities in seven areas of social function: activation-engagement, interpersonal communication, frequency of activities of daily living, competence at activities of daily living, participation in social activities, participation in recreational activities, and employment or occupational activity.
The Schedule for the Assessment of Insight (SAI; David, 1990) was used at baseline to assess three dimensions of insight: awareness of illness, the ability to correctly attribute psychotic experiences, and the need for treatment.

Movement disorders were assessed at both baseline and follow-up, using three rating scales. The Abnormal Involuntary Movements Scale (AIMS; Guy, 1976) was used to determine the presence of mild dyskinesia (rating of 'mild' in at least one body area), and tardive dyskinesia using Research Diagnostic Criteria (RDC): the presence of at least a 'moderate' rating in one or more body areas, or 'mild' movements in two or more body areas (Schooler \& Kane, 1982). The Extrapyramidal Side Effects Rating Scale (EPSE; Simpson \& Angus, 1970) was used to diagnose parkinsonism, the presence of the condition being defined as a total scale score of 3 or more. The Barnes Akathisia Rating Scale (BARS; Barnes, 1989) was used to identify akathisia, the criterion for the presence of the condition being a score of 2 or more on the global item.

Pre-morbid IQ was estimated with the National Adult Reading Test Revised (Nelson \& Willison, 1991) at baseline. At baseline and follow-up, measures of recognition memory, spatial span, spatial working memory, Tower of London planning and attentional set shifting were obtained using the Cambridge Automated Neuropsychological Test Battery (CANTAB; Sahakian \& Owen, 1992), run on an IBM-compatible PC with a touch-sensitive screen. We have previously described the nature of these tests, the performance measures used and the derivation of the test scores in our patients (Hutton et al. 1998).

Detailed information on the medication regimen during the follow-up period was obtained from the patients and their clinical notes. This methodology has been described previously (Kapasi et al. 2004). Patients were divided into those prescribed second-generation $(n=33)$ or first-generation $(n=20)$ antipsychotics throughout the follow-up period and those whose medication had been inconsistent for various reasons $(n=29)$, such as switching from one type of antipsychotic to another or receiving a combination.

\section{Statistical methods}

Data were analysed using SPSS version 14 (SPSS Inc., Chicago, IL, USA). Comparisons between groups on each of the measures were conducted using separate analyses of variance (ANOVAs) with appropriate post hoc tests, $t$ tests or $\chi^{2}$ tests as indicated.

\section{Results}

Alcohol and drug use data were obtained at 1 year on $85(56 \%)$ of the original 152 patients (Barnes et al. 2006) 
Table 1. Comparison of study subgroups and those lost to follow-up on baseline demographic and clinical variables

\begin{tabular}{|c|c|c|c|c|}
\hline & \multirow[b]{2}{*}{$\begin{array}{l}\text { Lost to } \\
\text { follow-up } \\
(n=67)\end{array}$} & \multicolumn{3}{|c|}{ Study follow-up sample $(n=85)$} \\
\hline & & $\begin{array}{l}\text { No history of } \\
\text { substance use } \\
(n=22)\end{array}$ & $\begin{array}{l}\text { History of } \\
\text { substance } \\
\text { use }(n=63)\end{array}$ & $\begin{array}{l}\text { Comparison of those } \\
\text { with and without } \\
\text { a history of substance } \\
\text { use at baseline }\left(t / \chi^{2}\right)\end{array}$ \\
\hline Age at testing in years, mean (S.D.) & $25.89(7.28)$ & $27.60(10.49)$ & $23.89(6.54)$ & 1.55 \\
\hline Gender: M/F & $48 / 19$ & $14 / 8$ & $48 / 15$ & 1.3 \\
\hline Pre-morbid IQ, mean (s.D.) & $98.73(10.40)$ & $99.32(8.95)$ & $100.06(10.95)$ & -0.26 \\
\hline \multicolumn{5}{|l|}{ Mental state, mean (S.D.) } \\
\hline \multicolumn{5}{|l|}{ Symptom-based syndrome scores } \\
\hline Negative syndrome & $0.41(0.25)$ & $0.39(0.29)$ & $0.43(0.26)$ & -0.69 \\
\hline Positive syndrome & $0.75(0.49)$ & $0.58(0.26)$ & $0.67(0.25)$ & -1.30 \\
\hline Disorganization syndrome & $0.39(0.29)$ & $0.39(0.30)$ & $0.45(0.29)$ & -0.77 \\
\hline CGI severity score & $4.73(1.16)$ & $3.90(1.17)$ & $4.80(1.12)$ & $-3.08^{*}$ \\
\hline Depression: MADRS score & $17.21(9.55)$ & $17.32(8.99)$ & $18.72(10.74)$ & -0.54 \\
\hline \multicolumn{5}{|l|}{ Social function, mean (S.D.) } \\
\hline Social Function Scale score & $110.60(12.05)$ & $114.60(10.66)$ & $110.57(12.03)$ & 1.37 \\
\hline \multicolumn{5}{|l|}{ Movement disorder, $n(\%)$} \\
\hline Presence of parkinsonism: EPSE criterion & $17(28)$ & $4(18)$ & $12(19)$ & 0 \\
\hline Presence of akathisia: BARS criterion & $12(20)$ & $3(14)$ & $12(19)$ & 0.27 \\
\hline \multicolumn{5}{|l|}{ Presence of tardive dyskinesia } \\
\hline AIMS: mild dyskinesia criteria & $6(10)$ & $3(14)$ & $13(21)$ & 0.41 \\
\hline AIMS: RDC & $4(7)$ & $2(9)$ & $8(13)$ & 0.15 \\
\hline
\end{tabular}

S.D., Standard deviation; M, male ; F, female; IQ, intelligence quotient; CGI, Clinician Global Impression scale; MADRS,

Montgomery-Asberg Depression Rating Scale; EPSE, Extrapyramidal Side Effects Rating Scale; BARS, Barnes Akathisia Rating Scale; AIMS, Abnormal Involuntary Movements Scale; RDC, Research Diagnostic Criteria.

${ }^{*} p<0.05$.

assessed at initial presentation to services. The median follow-up period was 14 months (range 5-102). Sixtyseven patients of the original cohort had missing data regarding the presence of substance use at follow-up due to being uncontactable $(n=20)$, deceased $(n=3)$ or refusing further study involvement $(n=44)$. The 85 follow-up subjects did not differ significantly from the 67 subjects lost to follow-up on baseline variables of age at first presentation to services with schizophrenia, gender, history of substance use, syndrome scores, depression rating, severity of illness or social function (see Table 1, range of $t$ values: -1.71 to 1.68 ; range of $\chi^{2}$ values: $0.32-2.71$ ). In the subgroup of subjects with insight scores available, those lost to follow-up had a significantly lower mean SAI score at baseline $(t=-2.40, \mathrm{df}=88, p=0.018)$.

\section{Substance use and clinical outcome}

Within the follow-up sample, those subjects with and without a report of lifetime substance use (drugs and/or alcohol but not including tobacco use) at baseline were compared with respect to: age at baseline testing, gender, mental state variables, movement disorder and social function (see Table 1). The only significant difference revealed was that the patients with a history of substance abuse had a significantly higher mean CGI score, indicating a more severe illness. Repeating the analyses, comparing those with and without a report of non-alcohol drug use only, revealed similar results, with those patients reporting a history of drug use without alcohol problems demonstrating significantly higher CGI scores $(t=-3.00$, $\mathrm{df}=75, p=0.004)$.

To examine change in symptoms and social function over time in these two groups, repeated measures ANOVAs were performed with factors of time (baseline and follow-up) and group (subjects with and without a report of any lifetime substance use at baseline). Both groups improved significantly over time on MADRS, CGI and the three schizophrenia syndrome scores (range of $F$ values: 31.78-113.19). There was a significant group effect for CGI $[F(1,71)=6.37, p=0.014]$, demonstrating that those 
Table 2. Comparison of follow-up clinical variables for the three substance use subgroups

\begin{tabular}{|c|c|c|c|c|}
\hline & \multicolumn{3}{|c|}{ Main substance use follow-up subgroups } & \multirow[b]{2}{*}{$F / \chi^{2}$} \\
\hline & $\begin{array}{l}\text { Persistent non-users } \\
(n=23)\end{array}$ & $\begin{array}{l}\text { Persistent users } \\
(n=21)\end{array}$ & $\begin{array}{l}\text { Baseline only users } \\
(n=36)\end{array}$ & \\
\hline \multicolumn{5}{|l|}{ Mental state, mean (s.D.) } \\
\hline \multicolumn{5}{|l|}{ Symptom-derived syndrome score } \\
\hline Negative syndrome & $0.17(0.24)$ & $0.29(0.29)$ & $0.21(0.24)$ & 1.165 \\
\hline Positive syndrome & $0.19(0.28)$ & $0.40(0.37)$ & $0.17(0.24)$ & $4.200^{*}$ \\
\hline Disorganization syndrome & $0.05(0.21)$ & $0.15(0.25)$ & $0.05(0.15)$ & 1.912 \\
\hline CGI severity score & $1.30(1.21)$ & $2.59(2.02)$ & $1.32(1.10)$ & $5.216^{*}$ \\
\hline Depression: MADRS score & $4.78(6.60)$ & $10.45(11.26)$ & $5.11(7.23)$ & $3.248^{*}$ \\
\hline \multicolumn{5}{|l|}{ Social function, mean (s.D.) } \\
\hline SFS score & $114.05(11.08)$ & $111.40(11.95)$ & $116.75(9.19)$ & 1.458 \\
\hline \multicolumn{5}{|l|}{ Insight, mean (S.D.) } \\
\hline SAI score & $13.22(5.89)$ & $11.60(5.10)$ & $12.40(4.58)$ & 0.247 \\
\hline \multicolumn{5}{|l|}{ Presence of movement disorder, $n(\%)$} \\
\hline Parkinsonism: EPSE criteria & $2(10)$ & $1(6)$ & $3(10)$ & 0.192 \\
\hline Akathisia: BARS criteria & $3(14)$ & $3(14)$ & $2(6)$ & 1.240 \\
\hline AIMS: mild dyskinesia criteria & $2(10)$ & $2(11)$ & $4(12)$ & 0.070 \\
\hline AIMS: RDC & $2(10)$ & $2(11)$ & $5(15)$ & 0.453 \\
\hline
\end{tabular}

CGI, Clinician Global Impression scale; MADRS, Montgomery-Asberg Depression Rating Scale; SFS, Social Function Scale; SAI, Schedule for Assessment of Insight; EPSE, Extrapyramidal Side Effects Rating Scale; BARS, Barnes Akathisia Rating Scale; AIMS, Abnormal Involuntary Movements Scale; RDC, Research Diagnostic Criteria.

${ }^{*} p<0.05$.

with a history of substance use were considered to be more ill. There were no main effects of group for any other clinical measures; the highest $F$ was for the positive syndrome scores $[F(1,83)=1.63$, N.s.]. SFS showed no significant improvement over time in either group. There were no significant effects of group $\times$ time. Limiting the analysis to those with or without a lifetime history of non-alcohol substance use did not alter the results.

To further examine the association between substance use and clinical outcome, the follow-up sample was divided into four groups: the 23 subjects reporting no substance use at any time ('persistent nonusers'); the 21 subjects reporting lifetime use at baseline and current use at follow-up ('persistent users'); the 36 subjects reporting lifetime use at baseline but no report of current use at follow-up ('baseline only users'); and the two subjects reporting no substance use at baseline but current use at follow-up. Given the small number of patients in the last group, this was excluded from further analysis. Table 2 provides details of clinical variables for the three groups (nonusers, persistent users and baseline only users) at follow-up. The information in the table shows that at follow-up the persistent users had significantly higher scores for the positive syndrome, overall severity of illness (CGI) and depressive features (MADRS).
To examine change in symptoms and social function over time in these three subgroups, repeated measures ANOVAs were again performed with factors of time (baseline and follow-up) and group (nonusers, persistent users and baseline only users). Initially, each of the symptom-based syndromes was examined separately. The main effects of time revealed significant improvement in negative $[F(1,77)=32.30$, $p<0.001]$, positive $[F(1,77)=80.50, p<0.001]$ and disorganization $[F(1,77)=66.71, p<0.001]$ syndrome scores. There were no main effects of group for negative $[F(2,77)=0.64$, N.s.] or disorganization syndrome scores $[F(2,77)=0.88]$, but there was a trend for the groups to differ with respect to positive syndrome scores $[F(2,77)=2.66, p=0.076]$. Similarly, group $\times$ time interaction effects were not significant for negative $[F(2,77)=0.88$, N.s.] and disorganization $[F(2,77)=0.64$, N.s. $]$ syndromes, but positive syndrome scores changed differently over time across the groups $[F(2,77)=5.50, p<0.006]$. Least significant difference (LSD) post hoc analyses showed that the persistent users improved less than the baseline only users $(p<0.05)$. Figure 1 displays the positive syndrome (hallucinations and delusions) scores at baseline and follow-up for the three substance use subgroups.

The same analysis was then performed on the remaining clinical variables. The main effects of time 


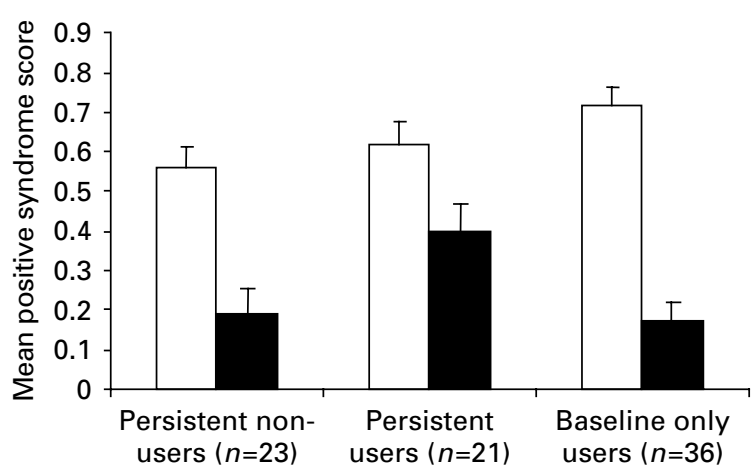

Fig. 1. Comparison of three main substance use follow-up subgroups at baseline $(\square)$ and follow-up $(\boldsymbol{\square})$ : positive symptom syndrome.

revealed significant improvement on the MADRS scores $[F(1,71)=52.92, p<0.001]$ and the CGI $[F(1,65)=121.55, p<0.001]$ but not SFS $[F(1,74)=0.30$, N.s.]. There was no main effect of group on the MADRS $[F(2,71)=0.70$, N.s. $]$ or SFS $[F(2,74)=0.71$, N.s. $]$. There was a significant group effect for CGI $[F(2,65)=6.29$, $p<0.003$, with persistent non-users having significantly less severe illness at baseline and follow-up than either persistent users or baseline only users. There were no group $\times$ time effects: the highest $F$ was for the SFS score $[F(2,74)=2.00$, N.s.].

An analysis of substance use profile and type of medication prescribed revealed no differences in the proportion of patients in each of the subgroups who had received purely first- or second-generation antipsychotics or a mixture of the two $\left(\chi^{2}=0.60, \mathrm{df}=4\right.$, N.s.).

\section{Substance use and cognitive function}

The following variables were used to analyse cognitive function: pre-morbid IQ, spatial span; spatial working memory errors; Tower of London perfect solutions planning score; stage reached on the attentional set shifting task; pattern recognition memory number correct. No significant differences were found between patient groups with and without a history of substance use at baseline (range of $t$ values for all measures was -0.85 to 0.81 ). To examine change in cognitive function over time in these two groups, repeated measures ANOVAs were performed. Analysis of the main effects of time revealed significant improvement in spatial working memory $[F(1,67)=9.63, p=0.003]$ and spatial span $[F(1,65)=5.64, p=0.02]$, with a trend for improvement in planning $[F(1,63)=2.85, p=0.07]$. By contrast, main effects of time were not significant for recognition memory $[F(1,63)=0.64$, N.s.] or stage reached on attentional set shifting $[F(1,61)=1.89$, N.s.] There were no main effects of group for any of the measures (highest $F$ was for the pattern recognition memory task $[F(1,63)=1.09$, N.s.]. Similarly, there were no significant effects of group $\times$ time for spatial span $[F(1,65)=0.10$, N.s.], recognition memory score $[F(1,63)=0.24$, N.S.], attentional set shifting stage reached $[F(1,61)=0.31$, N.s.] or planning $[F(1,63)=$ 0.39 , N.s.]. However, there was a significant interaction for spatial working memory errors $[F(1,67)=4.61$, $p=0.04$ ] due to the group reporting no drug use at baseline showing a significant improvement [mean reduction in errors: 11.09 (s.E. $=4.02) ; F(1,67)=11.01$, $p=0.001]$ over the follow-up period, which was not found in the group reporting substance abuse [mean reduction in errors: 2.02 (s.E. $=2.75) ; F(1,67)<1$, N.s.]. Repeating the analysis with only those subjects with or without a lifetime history of non-alcohol substance use at baseline revealed essentially similar findings. Further analysis comparing spatial working memory performance and pattern of substance use over the follow-up period in subgroups such as persistent users and baseline only users was precluded by the small numbers.

\section{Use of substances over the follow-up period}

Data on the full range of substance use at both baseline and follow-up were available for 81 of the follow-up sample.

\section{Smoking}

At first assessment, $49(60 \%)$ of the sample were smokers, and this figure had risen to $52(64 \%)$ at follow-up. Only eight out of the 49 smoking at baseline had stopped smoking, while 11 of the 32 non-smokers at baseline had started smoking over the follow-up period. Further analysis investigating the effects of tobacco alone on clinical and neuropsychological factors was omitted because at baseline all but nine of the 49 smokers used other substances.

\section{Alcohol use}

At baseline, 24 (30\%) of the subjects reported problem drinking, of whom 16 had evidence of dependent drinking. By the follow-up assessment, only seven of these 24 subjects still had a drinking problem, although there was evidence of dependent drinking in all but one. An additional five subjects had developed a drinking problem during the follow-up period, so that the total number with such a problem at the time of follow-up was $12(15 \%)$.

\section{Cannabis}

At baseline, 51 (63\%) subjects reported lifetime cannabis use, and $26(32 \%)$ reported current use at that time. At follow-up, 15 (18.5\%) were using the drug, 
only one of whom had not reported use of the drug at the initial assessment.

\section{Stimulants}

At baseline, 29 (36\%) subjects reported lifetime use of stimulants (predominantly amphetamine and cocaine), but only two (2.5\%) were using these drugs at follow-up.

\section{Other substances}

The baseline figures for the lifetime use of other substances were as follows: ecstasy (3,4-methylenedioxymethamphetamine, MDMA) 30 (37\%); hallucinogens (such as lysergic acid diethylamide, LSD) 28 (34.5\%); opiates $9(11 \%)$; barbiturates and/or benzodiazepines $11(13.5 \%)$; phencyclidine (PCP) and/or angel dust 6 $(7 \%)$; other substances (such as khat) six (7\%). At the time of the follow-up assessments, no one in the sample reported the use of any of these substances.

\section{Discussion}

\section{Reduction in substance use}

The findings suggest that in people with first-episode schizophrenia, a report of past or current co-morbid substance use at the time of first presentation to clinical services is a poor indicator of persistent substance use following the initiation of treatment. Despite the relatively high proportion of patients in the sample reporting a history of problem or dependent drinking and/or cannabis, stimulant or other drug use when first presenting to psychiatric services, the figures for current use at follow-up were relatively low. At followup, only two people in the sample were using stimulants and there was no reported use of substances such as ecstasy, hallucinogens, opiates, barbiturates, benzodiazepines or PCP.

With regard to cannabis, the most common, nonalcohol substance used, there was a marked reduction in the number of people in the sample reporting its current use from baseline to the end of a median follow-up period of more than a year. While nearly a third $(32 \%)$ of patients reported current cannabis use at initial presentation, only $14(17 \%)$ were still using at follow-up, although one other patient had started using the drug during that period. These findings are in line with those of Caspari (1999), who followed up a sample of people with schizophrenia of relatively early onset, with a history of cannabis use at their index admission. Reassessed more than 5 years later, nearly half the cases (48\%) had discontinued any substance use. Similarly, in a retrospective study of first-episode psychosis, Lambert et al. (2005) reported a reduction in prevalence of co-morbid substance use disorder from $62 \%$ at baseline to $36 \%$ in those completing 18 months of treatment in an early intervention programme. Furthermore, in a prospective study of first-episode psychosis by Wade et al. (2006), there was a significant reduction in substance use over a 15-month follow-up period. Specifically, the proportion using cannabis fell from $63 \%$ to $42 \%$.

The patients in our sample were not exposed to any treatment programme targeted at substance use. It is therefore plausible but entirely speculative that the decline in substance use may be partly attributable to the non-specific intervention of antipsychotic medication. There are several reports suggesting that antipsychotic drugs, particularly second-generation drugs such as clozapine, olanzapine, quetiapine and risperidone (Drake et al. 2000; Smelson et al. 2002; Potvin et al. 2003), may be associated with full or partial remission of substance use. However, in the present study, second-generation antipsychotics showed no advantage in relation to use of substances at follow-up.

\section{Symptoms and illness severity}

For the overall sample, there was no significant relationship between lifetime report of substance use at initial presentation and clinical outcome over the follow-up period, in terms of global severity of illness, social function or severity of psychotic or depressive symptoms. This is in line with the findings of the study by Lambert et al. (2005): in first-episode psychosis, baseline substance use disorder had no significant influence on symptom remission at 18 months' follow-up. However, the findings of the present study confirm that persistent substance use following presentation with first-episode schizophrenia can be associated with greater symptom severity in respect of positive symptoms such as hallucinations and delusions and depressive symptoms, but not negative symptoms (Bühler et al. 2002; Grech et al. 2005). There are several possible explanations for this association, and they are not mutually exclusive: first-episode schizophrenia with continuing co-morbid substance use may be less responsive to antipsychotic medication (Green et al. 2004), or substance use could be exacerbating the positive symptoms (Grech et al. 2005). In addition, patients with more severe psychotic illness may be more likely to use substances as selfmedication, to relieve depression or positive symptoms, the latter being perhaps less plausible, with little supportive evidence (Addington \& Duchak, 1997; Spencer et al. 2002). A further possibility is that the poor clinical outcome in those with persistent comorbid substance use reflects an association with poor adherence with treatment. However, in a previous 
study of patients derived from the West London first-episode schizophrenia cohort, we failed to find a relationship between co-morbid substance use and adherence to medication (Mutsatsa et al. 2003), and Sorbara et al. (2003) reported that persistent substance use after first admission for psychosis had a deleterious impact on clinical outcome independent of medication adherence.

\section{Cognitive impairment}

Although cognitive deficits in association with alcohol and drug use have been extensively reported, they have tended not to emerge in studies of co-morbid substance use in schizophrenia. For example, Sevy et al. (2001) failed to find an association between lifetime substance use in first-episode patients and cognitive impairment, and Joyal et al. (2003) found no association between co-morbid substance use and neuropsychological performance in a sample of men with established schizophrenia.

We have previously demonstrated that patients with first-episode schizophrenia are impaired on aspects of executive function, including SWM (Hutton et al. 1998; Joyce et al. 2002). In the present study, we examined the possible interactions between baseline substance use or no substance use and change in neurocognitive performance measures over the follow-up period. The only significant interaction was with SWM: a report of no lifetime substance use at baseline was associated with a significantly greater improvement in SWM performance (see earlier comments about controlling for baseline performance).

The findings of a specific improvement in one subgroup of patients and on one of several tests mitigates an explanation of this finding in terms of 'practice effects'. In support of this, our unpublished findings of test-retest performance after a 1-year interval in 42 normal control subjects showed no significant changes on the SWM test.

A preferred interpretation of this finding is that the effects of past use of substances may delay or otherwise impede recovery of SWM performance over the first year or so of treatment. Impairment of working memory may be attributable to several of the substances reported, either alone or in combination. An association between chronic alcohol consumption and deficits on working memory tasks has been found in both animal (Santin et al. 2000) and human studies (Ambrose et al. 2001; Weissenborn \& Duka, 2003). With regard to non-alcohol substance use, Block et al. (2002) concluded that chronic drug use is associated with a range of cognitive impairments, including memory problems, which may fail to show improvement even after several months of abstinence. Specifically, long-term and heavy users of cannabis may experience subtle neuropsychological deficits in attention and memory that may or may not persist after prolonged abstinence, and that require compensatory effort, calling upon additional brain regions, when trying to meet the demands of neuropsychological tasks (Lundqvist, 2005). Cannabis has been associated with disruption of working memory in samples of substance users, but only with long-term use (Fletcher et al. 1996). There is some evidence that ecstasy (MDMA) can lead to impaired neuropsychological performance in young people, which may not be reversed by prolonged abstinence (Battachary \& Powell, 2001; Morgan et al. 2002), but whether or not working memory is a core deficit remains unclear (GouzoulisMayfrank et al. 2000; Rodgers, 2000; Battachary \& Powell, 2001; Morgan et al. 2002), and coincident cannabis use is an important potential confound in studies in this area (Rodgers, 2000; Croft et al. 2001). Finally, impairment on some tests of working memory has been reported for subjects whose primary drug of abuse was either amphetamines or heroin (Ornstein et al. 2000).

\section{Limitations of the study}

Perhaps the main limitation of this study is the relatively low proportion of patients reassessed at follow-up. This is relevant to the interpretation of the findings, in that there may have been some selective drop-out from the study, generating bias. However, in defence of the generalizability of the sample, those subjects successfully followed up could not be distinguished at baseline from those lost to follow-up on key clinical variables.

Another potential criticism relates to the reliability of self-report for assessing substance use. The disadvantages of such a method are selective underreporting of recent use and particular substances, such as stimulants and opiates (Magura \& Kang, 1996). Key advantages in the context of the present study were that it could provide information on drug history, age of onset and remote use, and identify pattern of use and dependence, as well as cover drugs, such as LSD and solvents, that would be difficult to test for with other methods. There is also evidence for the validity of self-reported substance use in various clinical groups, including young multiple drug users receiving treatment (Martin et al. 1988), out-patients diagnosed with substance use disorder and bipolar disorder/post-traumatic stress disorder (Weiss et al. 1998), and a mixed psychiatric and substance use population (Weaver et al. 2003).

As the majority of participants in this epidemiologically based study who had a history of substance use 
had lifetime use of more than one substance, the data do not allow for any conclusions regarding the effects of any particular substance.

\section{Clinical implications}

The findings of the present study add to the evidence that, for people with first-episode schizophrenia, continued substance use may worsen outcome, and stopping the use of substances, such as cannabis, may be associated with an improved outcome (Linszen et al. 1994). The findings also reinforce the argument that those involved in the care of people with first-episode schizophrenia need to identify substance use disorder early and develop strategies to limit continued substance use and prevent the problem developing in those not currently using (Addington \& Addington, 2001; Green et al. 2004). The findings also suggest that, at least in an urban, UK sample, a relatively high proportion of those with both schizophrenia and a report of lifetime substance use at first presentation to services will not be using alcohol or non-alcohol substances a year or so later, in the absence of any specific psychological interventions for substance use. Therefore, such interventions might be most effectively targeted on the minority exhibiting persistent substance use, in whom more severe residual positive symptoms may be seen.

Although use of most substances declined over the follow-up period, tobacco use proved to be an exception. The proportion of patients smoking showed a slight increase over the follow-up period. Wade et al. (2006) reported a similar finding; there was little change in the proportion of their cohort of patients with first-episode psychosis using tobacco over a 15month follow-up period. This area of dependency in people in the early stages of schizophrenia should be a priority area for further research on mechanisms and treatment possibilities.

\section{Acknowledgements}

This work was funded by the Wellcome Trust (Grant: 064607/Z/01/Z).

\section{Declaration of Interest}

T.R.E.B. has, on occasion, over the past few years acted as a consultant to the pharmaceutical industry (Servier, Bristol-Myers Squibb, Johnson \& Johnson).

\section{References}

Addington J, Addington D (2001). Impact of an early psychosis program on substance use. Psychiatric Rehabilitation Journal 25, 60-66.
Addington J, Duchak V (1997). Reasons for substance use in schizophrenia. Acta Psychiatrica Scandinavica 96, 329-333.

Ambrose ML, Bowden SC, Whelan G (2001). Working memory impairments in alcohol-dependent participants without clinical amnesia. Alcoholism: Clinical and Experimental Research 25, 185-191.

Andreasen N (1990). Methods for assessing positive and negative symptoms. In Schizophrenia: Positive and Negative Symptoms and Syndromes. Modern Problems in Pharmacopsychiatry (ed. N. Andreasen), pp. 73-85. Karger: Basel.

Asberg M, Montgomery SA, Perris C, Schalling D, Sedvall G (1978). A comprehensive psychopathological rating scale. Acta Psychiatrica Scandinavica 271 (Suppl.), 5-27.

Barnes TRE (1989). A scale for rating drug-induced akathisia. British Journal of Psychiatry 154, 486-491.

Barnes TRE, Mutsatsa SH, Hutton SB, Watt HC, Joyce EM (2006). Comorbid substance use and age at onset of schizophrenia. British Journal of Psychiatry 188, 237-242.

Battachary S, Powell JH (2001). Recreational use of 3,4-methylenedioxymethamphetamine (MDMA) or 'ecstasy' : evidence for cognitive impairment. Psychological Medicine 31, 647-658.

Birchwood M, Smith J, Cochrane R, Wetton S, Copestake S (1990). Social Functioning Scale: the development and validation of a new scale of social adjustment for use in family intervention programmes with schizophrenic patients. British Journal of Psychiatry 157, 853-859.

Block RI, Erwin WJ, Ghoneim MM (2002). Chronic drug use and cognitive impairments. Pharmacology, Biochemistry and Behavior 73, 491-504.

Bühler B, Hambrecht M, Löffler W, an der Heiden W, Häfner H (2002). Precipitation and determination of the onset and course of schizophrenia by substance use - a retrospective and prospective study of 232 population-based first illness episodes. Schizophrenia Research 54, 243-251.

Caspari D (1999). Cannabis and schizophrenia: results of a follow-up study. European Archives of Psychiatry and Clinical Neuroscience 249, 45-49.

Condren RM, O'Connor J, Browne R (2001). Prevalence and patterns of substance misuse in schizophrenia: a catchment area case-control study. Psychiatric Bulletin 25, 17-20.

Croft RJ, Mackay AJ, Mills AT, Gruzelier JG (2001). The relative contributions of ecstasy and cannabis to cognitive impairment. Psychopharmacology 153, 373-379.

David AS (1990). Insight and psychosis. British Journal of Psychiatry 156, 798-808.

Drake RE, Brunette MF (1998). Complications of severe mental illness related to alcohol and other drug disorders. In Recent Developments in Alcoholism (ed. M. Galanter), pp. 285-299. Plenum: New York.

Drake RE, Xie H, McHugo GJ, Green AI (2000). The effects of clozapine on alcohol and drug use disorders among patients with schizophrenia. Schizophrenia Bulletin 26, 441-449.

Duke PJ, Pantelis C, Barnes TRE (1994). South Westminster Schizophrenia Survey. Alcohol use and its relationship to 
symptoms, tardive dyskinesia and illness onset. British Journal of Psychiatry 164, 630-636.

Duke PJ, Pantelis C, McPhillips MA, Barnes TRE (2001). Comorbid substance misuse among people with schizophrenia in the community: an epidemiological study in central London. British Journal of Psychiatry 179, 501-513.

Fletcher JM, Page JB, Francis DJ, Copeland K, Naus MJ, Davis CM, Morris R, Krauskopf D, Satz P (1996). Cognitive correlates of long-term cannabis use in Costa Rican men. Archives of General Psychiatry 53, 1051-1057.

Gouzoulis-Mayfrank E, Daumann J, Tuchtenhagen F, Pelz S, Becker S, Kunert HJ, Fimm B, Sass H (2000). Impaired cognitive performance in drug free users of recreational ecstasy (MDMA). Journal of Neurology, Neurosurgery and Psychiatry 68, 719-725.

Grech A, Van Os J, Jones PB, Lewis SW, Murray RM (2005). Cannabis use and outcome of recent onset psychosis. European Psychiatry 20, 349-353.

Green AI, Tohen MF, Hamer RM, Strakowski SM, Lieberman JA, Glick I, Clark WS ; HGDH Research Group (2004). First-episode schizophrenia-related psychosis and substance use disorders: acute response to olanzapine and haloperidol. Schizophrenia Research 66, 125-136.

Guy W (1976). ECDEU Assessment Manual for Psychopharmacology, pp. 76-338. National Institute for Mental Health: Rockville, MD.

Hunt GE, Bergen J, Bashir M (2002). Medication compliance and comorbid substance abuse in schizophrenia: impact on community survival 4 years after a relapse.

Schizophrenia Research 54, 253-264.

Hutton SB, Puri BK, Duncan LJ, Robbins TW, Barnes TRE, Joyce EM (1998). Executive function in first-episode schizophrenia. Psychological Medicine 28, 463-473.

Joyal CC, Hallé P, Lapierre D, Hodgins S (2003). Drug abuse and/or dependence and better neuropsychological performance in patients with schizophrenia. Schizophrenia Research 63, 297-299.

Joyce E, Hutton S, Mutsatsa S, Gibbins H, Webb E, Paul S, Robbins T, Barnes TRE (2002). Executive dysfunction in first-episode schizophrenia and relationship to duration of untreated psychosis: the West London Study. British Journal of Psychiatry 181 (Suppl. 43), 38-44.

Kapasi M, Hutton SB, Mutsatsa S, Barnes TRE, Joyce EM (2004). Treatment effects of conventional and atypical antipsychotics on cognition following a first episode of schizophrenia. Journal of Psychopharmacology 18, A63.

Kavanagh DJ, Waghorn G, Jenner L, Chant DC, Carr V, Evans M, Hemnan H, Jablensky A, McGrath JJ (2004). Demographic and clinical correlates of comorbid substance use disorders in psychosis: multivariate analyses from an epidemiological sample. Schizophrenia Research 66, 115-124.

Lambert M, Conus P, Lubman DI, Wade D, Yuen H, Moritz S, Naber D, McGorry PD, Schimmelmann BG (2005). The impact of substance use disorders on clinical outcome in 643 patients with first-episode psychosis. Acta Psychiatrica Scandinavica 112, 141-148.
Liddle PF, Barnes TRE (1990). Syndromes of chronic schizophrenia. British Journal of Psychiatry 157, 558-561.

Linszen DH, Dingemans PM, Lenoir ME (1994). Cannabis abuse and the course of recent-onset schizophrenic disorders. Archives of General Psychiatry 51, 273-279.

Lundqvist T (2005). Cognitive consequences of cannabis use: comparison with abuse of stimulants and heroin with regard to attention, memory and executive functions. Pharmacology, Biochemistry and Behavior 81, 319-330.

Magura S, Kang SY (1996). Validity of self-reported drug use in high risk populations: a meta-analytical review. Substance Abuse and Misuse 31, 1131-1153.

Martin GW, Wilkinson DA, Kaur BM (1988). Validation of self-reported cannabis use by urine analysis. Addictive Behaviors 13, 147-150.

McCleery A, Addington J, Addington D (2006). Substance misuse and cognitive functioning in early psychosis: a 2 year follow-up. Schizophrenia Research 88, 187-191.

Montgomery SA, Asberg M (1979). A new depression scale designed to be sensitive to change. British Journal of Psychiatry 134, 382-389.

Morgan MJ, McFie L, Fleetwood H, Robinson JA (2002). Ecstasy (MDMA): are the psychological problems associated with its use reversed by prolonged abstinence? Psychopharmacology 159, 294-303.

Mutsatsa S, Joyce EM, Hutton S, Webb E, Gibbins H, Paul S, Barnes TRE (2003). Clinical correlates of early medication compliance: West London first episode schizophrenia study. Acta Psychiatrica Scandinavica 108, 439-446.

Nelson H, Willison J (1991). The Revised National Adult Reading Test (NART) - Test Manual, 2nd edn. NFER-Nelson: Windsor.

Ornstein TJ, Iddon JL, Baldacchino AM, Sahakian BJ, London M, Everitt BJ, Robbins TW (2000). Profiles of cognitive dysfunction in chronic amphetamine and heroin abusers. Neuropsychopharmacology 23, 113-126.

Pencer A, Addington J (2003). Substance use and cognition in early psychosis. Journal of Psychiatry and Neuroscience 28, 48-54.

Potvin S, Briand C, Proteau A, Bouchard RH, Lipp O, Lalonde P, Nicole L, Lesage A, Stip E (2005). CANTAB explicit memory is less impaired in addicted schizophrenia patients. Brain and Cognition 59, 38-42.

Potvin S, Stip E, Roy JY (2003). Clozapine, quetiapine and olanzapine among addicted schizophrenic patients: towards testable hypotheses. International Clinical Psychopharmacology 18, 121-132.

Rodgers J (2000). Cognitive performance amongst recreational users of 'ecstasy'. Psychopharmacology 151, 19-24.

Sahakian B, Owen A (1992). Computerised assessment in neuropsychiatry using CANTAB. Journal of the Royal Society of Medicine 85, 399-402.

Salyers MP, Mueser KT (2001). Social functioning, psychopathology and medication side effects in relation to substance use and abuse in schizophrenia. Schizophrenia Research 48, 109-123. 
Santin LJ, Rubio S, Begega A, Arias JL (2000). Effects of chronic alcohol consumption on spatial reference and working memory tasks. Alcohol 20, 149-159.

Schooler NR, Kane JM (1982). Research diagnoses for tardive dyskinesia. Archives of General Psychiatry 39, 486-487.

Sevy S, Robinson DG, Holloway S, Alvir JM, Woerner MG, Bilder R, Goldman R, Lieberman J, Kane J (2001).

Correlates of substance misuse in patients with firstepisode schizophrenia and schizoaffective disorder. Acta Psychiatrica Scandinavica 104, 367-374.

Simpson GM, Angus JWS (1970). A rating scale for extrapyramidal side-effects in drug-induced extrapyramidal disorders. Acta Psychiatrica Scandinavica 212, 11-19.

Smelson DA, Losonczy MF, Davis CW, Kaune M, Williams J, Ziedonis D (2002). Risperidone decreases craving and relapses in individuals with schizophrenia and cocaine dependence. Canadian Journal of Psychiatry 47, 671-675.

Sorbara F, Liraud F, Assens F, Abalan F, Verdoux H (2003). Substance use and the course of early psychosis: a 2-year follow-up of first-admitted subjects. Schizophrenia Research 18, 133-136.
Spencer CR, Castle D, Michie PT (2002). Motivations that maintain substance use among individuals with psychotic disorders. Schizophrenia Bulletin 28, 233-247.

Wade D, Harrigan S, Edwards J, Burgess PM, Whelan G, McGorry PD (2006). Course of substance misuse and daily tobacco use in first-episode psychosis. Schizophrenia Research 81, 145-150.

Weaver T, Madden P, Charles V, Stimson G, Renton A, Tyrer P, Barnes TRE, Bench C, Middleton H, Wright N, Paterson S, Shanahan W, Seivewright N, Ford C. on behalf of the Comorbidity of Substance Misuse and Mental Illness Collaborative (COSMIC) study team (2003). Comorbidity of substance misuse and mental illness in community mental health and substance misuse services. British Journal of Psychiatry 183, 304-313.

Weiss RD, Najavits LM, Greenfield SF, Soto JA, Shaw SR, Wynerm D (1998). Validity of substance use self-reports in dually diagnosed outpatients. American Journal of Psychiatry 155, 127-128.

Weissenborn R, Duka T (2003). Acute alcohol effects on cognitive function in social drinkers: their relationship to drinking habits. Psychopharmacology 165, 306-312. 